\title{
Characterization of Phytoconstituents and Exploration of Antioxidant and Free Radical Scavanging Activities of Citrus assamensis Leaf
}

\author{
Mohammad Shahriar ${ }^{1,2}$, Mohiuddin Ahmed Bhuiyan ${ }^{2}$ and Md. Sohel Rana ${ }^{1}$ \\ ${ }^{1}$ Department of Pharmacy, Jahangirnagar University, Savar, Dhaka, Bangladesh \\ ${ }^{2}$ Phytochemistry Research Laboratory, Department of Pharmacy, University of Asia Pacific, Dhaka, Bangladesh
}

(Received: 30 October, 2017; Accepted: 11 February, 2018; Published (web): 10 June, 2018)

\begin{abstract}
The aim of the current investigation was to identify bioactive secondary metabolites and compare the phytoconstituents and antioxidant profile of different leaf extracts of Citrus assamensis. Preliminary phytochemical screening of chloroform extract of $C$. assamensis indicated the presence of alkaloids, phytosterols, phenols, tannins, glycosides, saponins and flavonoids, whereas the methanol and ethanol extracts were found to contain no saponin. The screenings of the plant revealed that, the amount of phenols was higher in methanol extract, while the ethanol extract was found to be rich in flavonoid and total antioxidant capacity. Methanol extract of $C$. assamensis leaf showed potent nitric oxide and hydrogen peroxide scavenging activity having $\mathrm{IC}_{50}$ value of $137.85 \mathrm{and} 85 \mu \mathrm{g} / \mathrm{ml}$, respectively. The chloroform extract was found to be highly effective in DPPH free radical scavenging, reducing power, cupric reducing antioxidant capacity and superoxide dismutase activity when compared to the standard. In case of catalase assay, all the C. assemensis leaf extracts showed highest activity at $50 \mu \mathrm{g} / \mathrm{ml}$. In most cases, lowest concentration of test groups showed significant $(* * \mathrm{p}<0.01 \& * \mathrm{p}<0.05)$ peroxidase activity.
\end{abstract}

Key words: Citrus assamensis, phytochemical screening, antioxidant profile, free radical scavenging, catalase assay, peroxidase activity.

\section{INTRODUCTION}

Research with medicinal plants is considered a fruitful approach in the discovery for new drugs. The traditional system of medicine extensively uses plantderived compounds and formulations to modulate the immune system of the host. ${ }^{1}$ Now-a-days, in many parts of the world traditional medicine replaces conventional medicine because herbal remedies are cost effective, have minimum toxicity with reduced health hazards and are easily available in the market as compared to synthetic medicines. ${ }^{2}$ With multiple biological activities, many medicinal plants have antioxidant activity that is attracting more and more attention of several research teams for its role against several diseases such as cancer, atherosclerosis,

Correspondence to: Mohiuddin Ahmed Bhuiyan Cell: +88-01711172189

E-mail: mohiuddin@uap-bd.edu

Dhaka Univ. J. Pharm. Sci. 17(1): 29-36, 2018 (June) cardio-vascular events, diabetes, hypertension, and Alzheimer's disease. ${ }^{3,4}$ Recently, there is keen biomedical interest in the family Rutaceae (fruits) because their uses as raw are mainly associated with low risk of gastric, colorectal, esophageal and cancer diseases. Citrus is a promising source of vitamin C, folate, and flavonoids due to which citrus is used as a cancer preventing agent. ${ }^{5,6}$

Citrus assamensis, locally known as Satkora in Bangladesh, is a small tree, 4.5 to 7.5 meter tall and moderately branched and thorny plant of the family Rutaceae. The plant is used as medicine by local tribes of Assam, India. Leaves, flowers, and fruits of C. assamensis are used for treating dysentery, indigestion, pimples and intestinal worms. ${ }^{7}$ The objective of the present study was to evaluate the antioxidant potential, in vitro and in vivo free radical scavenging activity of methanol, ethanol and 
chloroform extracts of leaf of $C$. assamensis. The extracts were examined for different reactive oxygen species (ROS) scavenging activities including nitric oxide, hydrogen peroxide, DPPH, reducing power capacity, CUPRAC, superoxide dismutase, catalase activity and peroxide activity and for phenol and flavonoid contents and total antioxidant activity.

\section{MATERIALS AND METHODS}

Collection, identification and preparation of plant samples. Leaves of $C$. assamensis were collected from Jayantapur, Sylhet, Bangladesh and the plant was taxonomically identified with the help of Bangladesh National Herbarium, Mirpur, Dhaka (DACB; Accession Number- 38759). Leaves were sun dried for seven days and ground to a coarse powder using high capacity grinding machine (Jaipan Designer Mixer Grinder, India) and kept in cool, dark and dry place for further investigation.

Extraction procedure. The powdered plant material $(30 \mathrm{gm})$ was successively extracted in a soxhlet extractor at elevated temperature $\left(40-60^{\circ} \mathrm{C}\right)$ using methanol followed by ethanol and chloroform. After extraction all extracts were evaporated and kept in refrigerator $\left(4^{\circ} \mathrm{C}\right)$ for further investigations with their necessary markings for identification.

Experimental animal. Swiss Albino mice of either sex, 4-5 weeks of age, weighing between (1024) $\mathrm{gm}$ were collected from ICDDR,B, Dhaka. Animals were maintained under standard environmental conditions (temperature: $27 \pm 1^{\circ} \mathrm{C}$, relative humidity: $55-65 \%$ and 12 hour light/12 hour dark cycle) and they had free access to feed and water. The animals were acclimatized to laboratory condition for one week prior to experiments.

Photochemical screening. Different extracts were screened for the presence of alkaloids, phytosterols, phenols, tannins, glycosides, saponins and flavonoids by using standard protocols. ${ }^{8}$

Determination of total phenolic content. Total phenolic content of the extracts of $C$. assemensis was determined by using the Folin-Ciocalteu reagent with slight modification by Laboni et al. ${ }^{9}$
Determination of total flavonoid content. Total flavonoid content of the extracts of $C$. assamensis was determined by the aluminum chloride colorimetric method with slight modification by Shahriar et al. ${ }^{10}$

Determination of total antioxidant capacity. Total antioxidant capacities of the extracts of $C$. assemensis were determined by using the phosphomolybdenum method. ${ }^{10}$

Nitric oxide scavenging assay. Nitric oxide scavenging assay was conducted as described previously by using sodium nitroprusside. ${ }^{11}$

Hydrogen peroxide scavenging assay. Scavenging activity of the extracts were evaluated by hydrogen peroxide with slight modification by Mannan et al. ${ }^{12}$

DPPH free radical scavenging assay. The free radical scavenging capacity of the extracts was determined using DPPH with slight modification by Ali et al. ${ }^{13}$

Reducing power assessment. The reducing power of the extract of $C$. assamensis was determined by standard method with slight modification by Tania et al. ${ }^{14}$

Cupric reducing antioxidant capacity (CUPRAC). Cupric reducing antioxidant capacity was conducted by following published protocol with slight modification by Ali et al. ${ }^{13}$

Assay for super oxide dismutase (SOD) activity. Superoxide dismutase (SOD) determination assay was carried out using SOD determination kit according to the kit's protocol provided by SigmaAldrich. The SOD activity was then calculated using the following equation after measurement of the absorbance of the mixtures at $450 \mathrm{~nm}$ in a microplate reader.

$$
\begin{gathered}
\text { Inhibition activity }(\%)=\{[(\text { Blank } 1-\text { Blank } 3)- \\
(\text { Sample A - Sample A's Blank 2) }] \text { / (Blank } 1- \\
\text { Blank 3) }\} \text { x } 100
\end{gathered}
$$

In vivo peroxidase activity. For in vivo peroxidase activity fifty four (54) Albino Swiss mice of both sexes (10-20 gm) were randomly divided into 9 groups. Group-I animals served as normal control. 
Group-II animals served as toxic control, Group-III served as a standard group. Group-IV-V, VI-VII and VIII-IX animals were treated with daily doses of 100 and $200 \mathrm{mg} / \mathrm{kg}$ body weight, using the leaf extracts of methanol, ethanol and chloroform, respectively for 7 days. Peroxidase activity was carried out as described by Yen and Chen. ${ }^{15}$

In vivo catalase activity. Catalase activity determination assay was carried out using ab83464 Catalase Activity Kit (Colorimetric/Fluorometric) according to the kit's protocol.

Statistical analysis. Data was expressed as Mean \pm SEM (Standard error of Mean). The results were analyzed statistically by ANOVA followed by
Dunnet's test. Results with $\mathrm{p}<0.05, \mathrm{p}<0.01$ and $\mathrm{p}<0.001$ were considered statistically significant.

\section{RESULTS AND DISCUSSION}

Phytochemical screening. Presence of various bioactive secondary metabolites in plant extract might be responsible for medicinal attributes. In this study, various leaf extracts of $C$. assamensis were tested for different phytoconsituents using standard procedures where chloroform extract was found to contain more varieties of phytoconstituents (Table 1).

Table 1. Analysis of phytochemicals in the different extracts of $C$. assamensis.

\begin{tabular}{lccc}
\hline Phytochemical(s) & Methanol extract & Ethanol extract & Chloroform extract \\
\hline Alkaloid & + & + & + \\
Phytosterol & + & + & + \\
Phenol & + & + & + \\
Tannin & + & + & + \\
Glycoside & + & - & + \\
Saponin & - & + & + \\
Flavonoids & + & & + \\
\hline
\end{tabular}

$(+) /(-)=$ Present $/$ Absent

Determination of total phenolic content. Total phenolic content of the different extracts was determined by using the Folin-Ciocalteu reagent and was expressed as gallic acid equivalent per gram of plant extracts. The screenings of the plant revealed that, the amount of phenols was higher in the methanol extract $(3.11 \mathrm{mg} / \mathrm{gm})$ among the three extract (Table 2). The beneficial effects of the extracts might be derived from phenolic compounds and flavonoids which have been reported for their antioxidant activity in biological systems, acting as scavengers of singlet oxygen and free radicals. ${ }^{16,17}$

Determination of flavonoid content. The values of flavanoid content varied from 1.33 to 2.08 mg quercetin/gm (Table 2). Moreover, ethanol extract has been found to be rich in flavonoids with a value of $2.08 \mathrm{mg}$ quercetin/gm followed by chloroform and methanol leaf extract.

\section{Determination of total antioxidant capacity.} Total antioxidant capacities of the different extracts were determined by using the phosphomolybdenum method and were expressed as ascorbic acid equivalent per gram of plant extracts. The results indicate higher total antioxidant capacity of the ethanol (1.76 mg ascorbic acid/gm) and methanol (1.61 $\mathrm{mg}$ ascorbic acid/gm) extracts from that of chloroform extract (Table 2). According to a recent report, a highly positive relationship between total phenols and antioxidant activity appears to be the trend in many plant species. ${ }^{18}$

Nitric oxide scavenging assay. The NO scavenging activity of methanol, ethanol and chloroform extracts was compared with ascorbic acid and the results are given in figure 1. The methanol extract of $C$. assamensis leaf has potent NO scavenging activity $\left(\mathrm{IC}_{50}\right.$ value $137.85 \mu \mathrm{g} / \mathrm{ml}$ ) (Table 3 ). The scavenging activity of NO by the extracts was 
increased in dose dependent manner figure 1A. In the present study, the methanol and ethanol extracts revealed the lowest $\mathrm{IC}_{50}$ value, which indicated its powerful NO scavenger ability.

Hydrogen peroxide scavenging assay. Hydrogen peroxide $\left(\mathrm{H}_{2} \mathrm{O}_{2}\right)$ scavenging activity of methanol, ethanol and chloroform extracts were detected and compared with ascorbic acid and the results have been summarized in figure 1B. Among three extracts, the methanol extract was at the top position in depleting $\mathrm{H}_{2} \mathrm{O}_{2}$ with an $\mathrm{IC}_{50}$ value, 85 $\mu \mathrm{g} / \mathrm{ml}$ (Table 3 ). The percent inhibition of scavenging activity of $\mathrm{H}_{2} \mathrm{O}_{2}$ for all the extracts was presented in figure 1B. In the present study though the extracts showed good $\mathrm{H}_{2} \mathrm{O}_{2}$ scavenging activity but it was less effective than standard ascorbic acid.

Table 2. Total phenolic, flavonoid contents and antioxidant capacity of the different extracts of C. assamensis.

\begin{tabular}{lccc}
\hline Extracts & $\begin{array}{c}\text { Total Phenol Contents (mg/gm, } \\
\text { Gallic Acid Equivalent) }\end{array}$ & $\begin{array}{c}\text { Total Flavonoid Contents (mg/gm, } \\
\text { Quercetin Equivalent) }\end{array}$ & $\begin{array}{c}\text { Total Anti-oxidant capacity (mg/gm, } \\
\text { Ascorbic Acid Equivalent) }\end{array}$ \\
\hline Methanol & $3.11 \pm 2.65$ & $1.33 \pm 0.43$ & $1.61 \pm 0.12$ \\
Ethanol & $2.69 \pm 0.82$ & $2.08 \pm 1.63$ & $1.76 \pm 0.14$ \\
Chloroform & $2.53 \pm 0.61$ & $1.69 \pm 0.95$ & $1.35 \pm 0.11$ \\
\hline
\end{tabular}
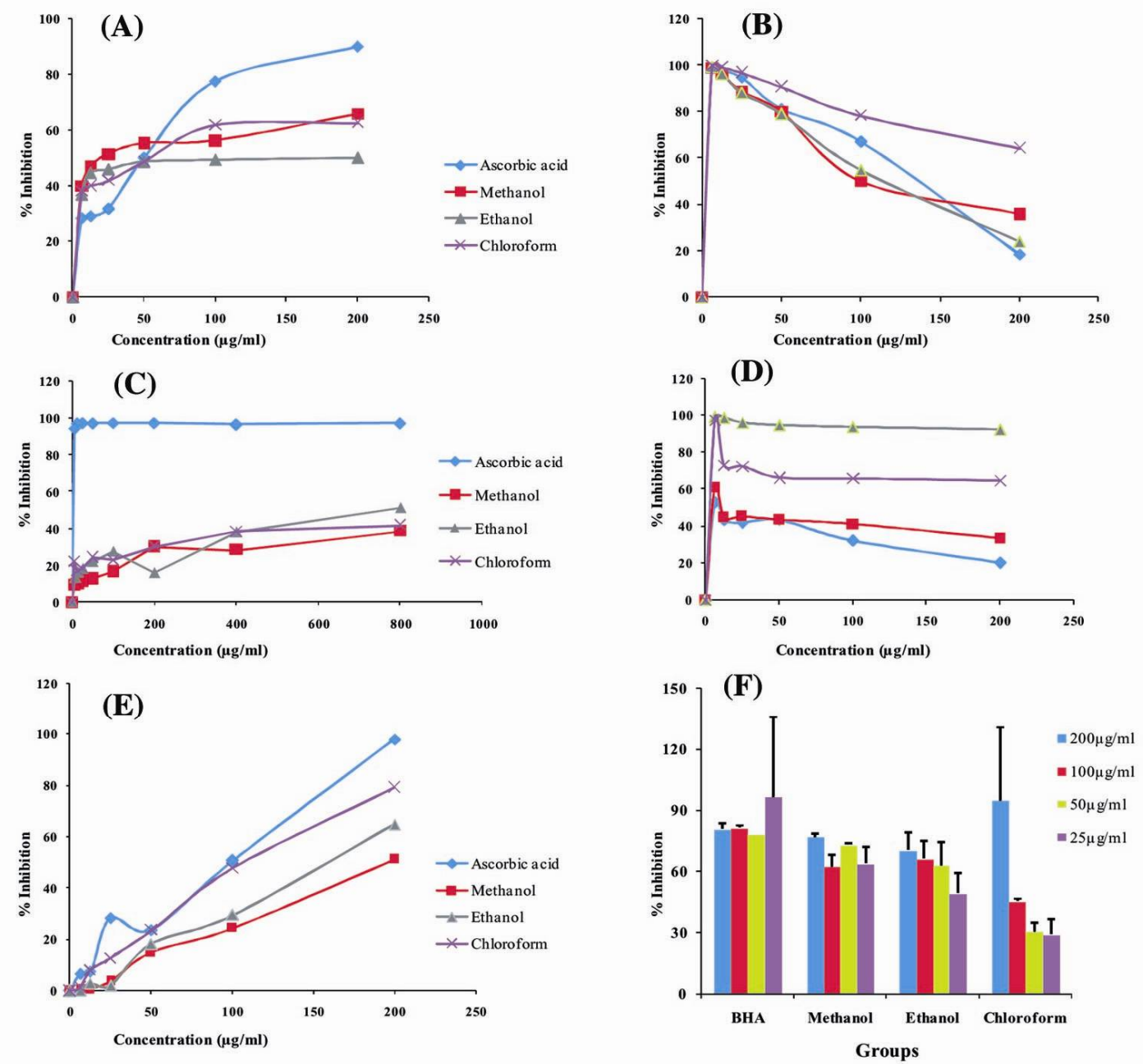

Figure 1. Percent inhibition of scavenging activity of nitric oxide (A), $\mathrm{H}_{2} \mathrm{O}_{2}$ (B), DPPH free radical (C), reducing power capacity (D), cupric reducing antioxidant capacity (E) and antioxidant activity (F) of the different extracts of $C$. assamensis leaf and standard. 
Table 3. $\mathrm{IC}_{50}$ values $(\mu \mathrm{g} / \mathrm{ml})$ of different leaf extracts of $C$. assamensis in nitric oxide scavenging, hydrogen peroxide scavenging, DPPH scavenging and reducing power capacity assay.

\begin{tabular}{lcccc}
\hline Extracts / Standard & $\begin{array}{c}\text { Nitric oxide scavenging } \\
(\mu \mathrm{g} / \mathrm{ml})\end{array}$ & $\begin{array}{c}\text { Hydrogen peroxide } \\
\text { scavenging } \\
(\mu \mathrm{g} / \mathrm{ml})\end{array}$ & $\begin{array}{c}\text { DPPH scavenging } \\
(\mu \mathrm{g} / \mathrm{ml})\end{array}$ & $\begin{array}{c}\text { Reducing power } \\
\text { capacity assay } \\
(\mu \mathrm{g} / \mathrm{ml})\end{array}$ \\
\hline Ascorbic acid & 162.5 & 147 & 5.69 & 119.85 \\
Methanol & 137.85 & 85 & 4.89 & 134.85 \\
Ethanol & 139.85 & 113.75 & 3.04 & 132 \\
Chloroform & 156 & 125 & 2.34 & 122.75 \\
\hline
\end{tabular}

DPPH free radical scavenging assay. The model of scavenging the stable DPPH free radical is a widely used method to evaluate the free radical scavenging ability of various samples including plant extracts. The DPPH free radical scavenging activity of methanol, ethanol and chloroform extracts were detected and compared with ascorbic acid and the results are shown in figure $1 \mathrm{C}$. The percent inhibition at different concentration of methanol, ethanol and chloroform extracts as well as standard ascorbic acid was calculated by linear regression analysis. All the plant extracts showed dose dependent scavenging of DPPH free radicals at different concentrations. In comparison to standard, methanol, ethanol and chloroform extracts showed $\mathrm{IC}_{50}$ values of $4.89,3.04$ and $2.34 \mu \mathrm{g} / \mathrm{ml}$ respectively (Table 3 ). The results indicated that among all tested extracts, the chloroform extract was found to be highly effective having $\mathrm{IC}_{50}$ value of $2.34 \mu \mathrm{g} / \mathrm{ml}$ (Table 3 ). In the present study, $\mathrm{IC}_{50}$ of ascorbic acid was found 5.69 $\mu \mathrm{g} / \mathrm{ml}$. Though the extracts showed good free radical scavenging activity but it was less effective than the standard. The result of the present study is consistent with previous studies with different extracts of Citrus species. ${ }^{19}$

Reducing power capacity. In reducing power capacity assessment, the extracts were found to display high to moderate reducing power. Reducing power was found to increase with increasing concentration of the extracts in all cases and was comparable to the standard ascorbic acid (Figure 1D). Most satisfactory $\mathrm{IC}_{50}$ value was observed in chloroform extract $(122.75 \mu \mathrm{g} / \mathrm{ml})$ when compared to

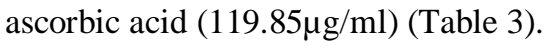

Cupric reducing antioxidant capacity (CUPRAC). Reduction of $\mathrm{Cu}^{2+}$ ion to $\mathrm{Cu}^{+}$was found to rise with increasing concentrations of the different extracts. The standard ascorbic acid showed highest reducing capacity. Among the extracts, chloroform extract of $C$. assamensis showed maximum reducing capacity which was comparable to ascorbic acid. The cupric reducing antioxidant capacity by the extract was increased in dose dependent manner (Figure 1E). In the present study, the CUPRAC value ranking was similar to that of the DDPH value, which may be due to the similar antioxidant mechanisms involved.

Superoxide dismutase (SOD) activity assay. Superoxide dismutase (SOD) is one of the key enzymes which becomes involved in cellular defense against reactive oxygen species in living organisms; hence it is an important indicator of antioxidant capacity. ${ }^{20}$ The results of SOD activity assay (figure 1F) showed that, all samples including BHA (5 $\mathrm{mg} / \mathrm{ml}$ ) had the activity with highest antioxidant potential obtained from chloroform extract followed by methanol and ethanol extract. However, the inhibition rate of chloroform extract is higher than positive control (BHA) in case of $200 \mu \mathrm{g} / \mathrm{ml}$ concentration. As shown in figure $1 \mathrm{~F}$, the superoxide radical scavenging activities of the plant extracts and the reference compound are increased markedly with increasing concentrations. The results suggest that the plant extracts are more potent scavengers of superoxide radical than the standard BHA.

In vivo catalase (CAT) activity. Catalase is an enzymatic antioxidant widely distributed in all animal tissues including $\mathrm{RBC}$ and liver. In result analysis of catalase activity test ELISA $(570 \mathrm{~nm})$ 
reading was collected after 30 minutes of incubation, where the lowest concentration groups $(50 \mu \mathrm{g} / \mathrm{ml})$ showed highest catalase activity rather than highest concentration $(800 \mu \mathrm{g} / \mathrm{ml})$ groups. Catalase decomposes hydrogen peroxide and helps protect the tissues from highly reactive hydroxyl radicals. ${ }^{21}$ In case of catalase assay $C$. assemensis leaf extracts like methanol $200(17.96 \mathrm{mU} / \mathrm{ml})$, ethanol $100 \& 200$ (192.5 mU/ml, $155.4 \mathrm{mU} / \mathrm{ml})$, chloroform $100 \& 200$ $(155.4 \mathrm{mU} / \mathrm{ml}, 23.2 \mathrm{mU} / \mathrm{ml})$ showed highest activity at lowest concentration $(50 \mu \mathrm{g} / \mathrm{ml})$. Exceptionally methanol $200(190.75 \mathrm{mU} / \mathrm{ml})$ at $200 \mu \mathrm{g} / \mathrm{ml}$ concentration showed catalase activity almost same as ethanol $100 \quad(192.5 \quad \mathrm{mU} / \mathrm{ml})$ at $50 \mu \mathrm{g} / \mathrm{ml}$ concentration with significance $* \mathrm{p}<0.05$. From Figure $2 \mathrm{~A}$ and $2 \mathrm{~B}$, it can be observed that ethanol 200 group at $200 \mu \mathrm{g} / \mathrm{ml}$ showed significant catalase activity $(* * \mathrm{p}<0.01,128.11 \mathrm{mU} / \mathrm{ml})$ in comparison with $50 \mu \mathrm{g} / \mathrm{ml}$ concentration $(155.4 \mathrm{mU} / \mathrm{ml})$ but showing lower catalase activity.
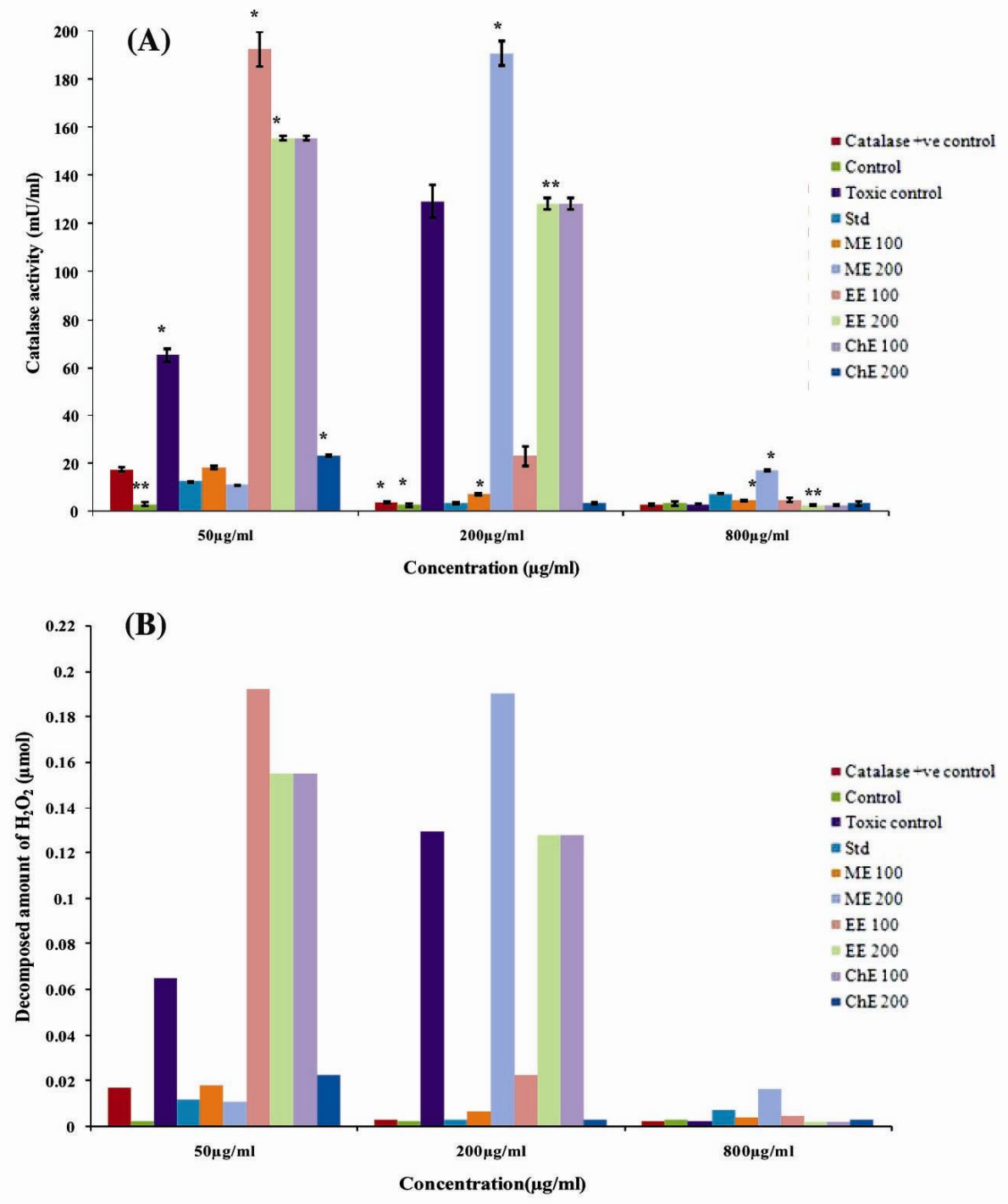

Values are mean \pm SEM $(n=6),(* \mathrm{p}<0.05),(* * \mathrm{p}<0.01)$ significantly different when compared with the corresponding value of standard group, done by independent sample t-test

Figure 2. Results of catalase activity of leaf extracts of C. assamensis along with catalase positive control, normal control, toxic control and standard (A) and considering amount of decomposed hydrogen peroxide against concentration of different groups (B). 
In vivo peroxidase activity. Figure 3 (A-E) showed the peroxidase activity test, which was collected by using ELISA $(570 \mathrm{~nm})$ reading in every 15 minutes (starting from 15 minutes to 75 minutes). The results represents when the concentration (2 nmol) for shown significant peroxidase activity for methanol, ethanol and chloroform extracts with the dose of $100 \mathrm{mg} / \mathrm{kg}$ body weight in first 15 minute rather than highest concentration $(5 \mathrm{nmol}) . C$. assemensis leaf extract showed a static peroxidase activity. In 5 times observation in 15 minutes gap; highest peroxidase activity was observed after $1^{\text {st }} 15$ minute reading. Then after 30, 45, 60 and 75 minutes reading $C$. assemensis leaf extracts and standard also showed static rate of peroxidative activity. In most cases 2 nmol concentration of test groups (toxic control, methanol 200, ethanol 100 and 200, chloroform 100 and 200) showed significant $(* * \mathrm{p}<0.01 \& * \mathrm{p}<0.05)$ peroxidase activity. Each test group showed their highest activity at low concentration and lowest activity in highest concentration. In comparison with in-vitro hydrogen peroxide scavenging assay result support this in-vivo result (Figure 3).
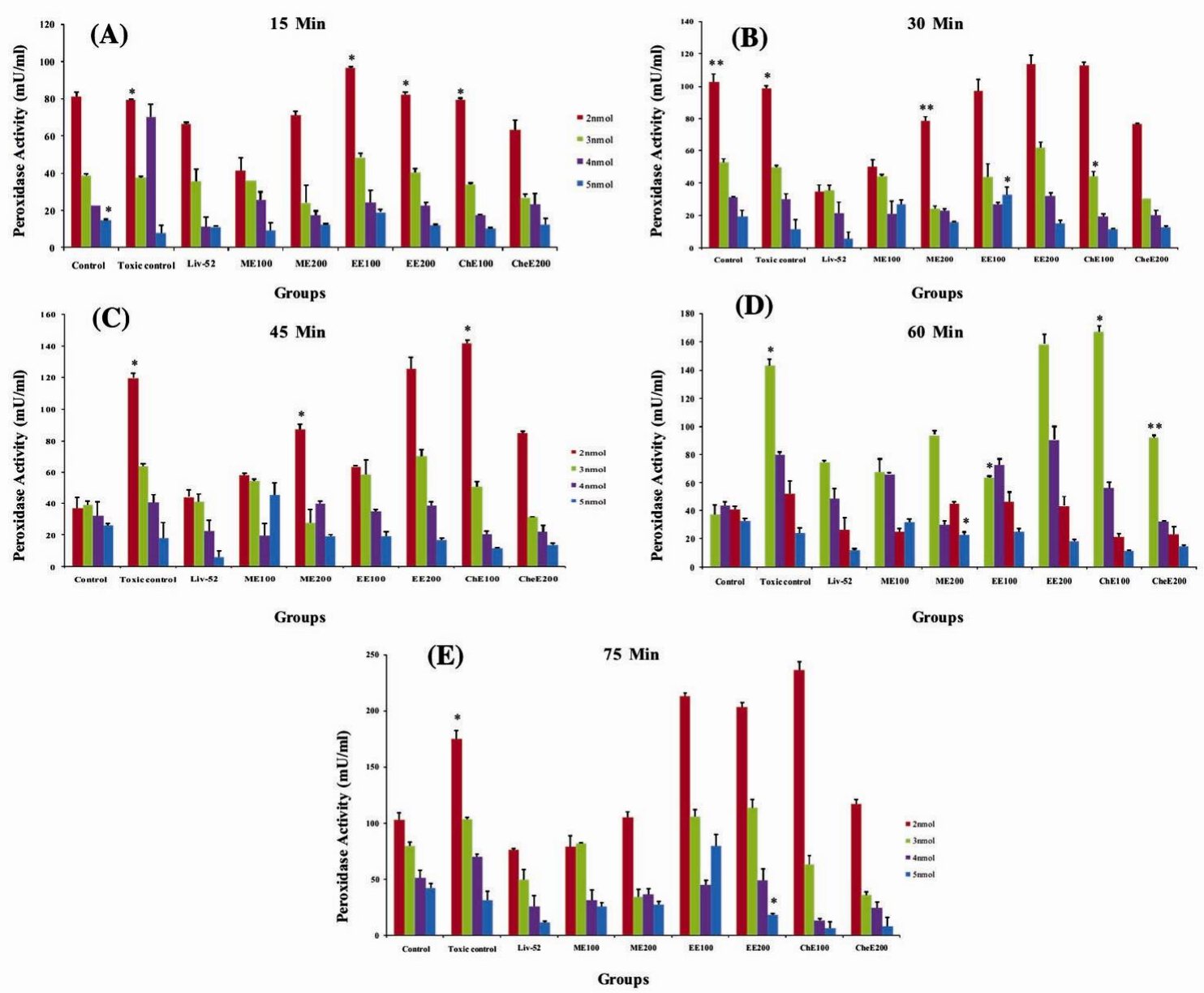

Figure 3. Results of peroxidase activities of leaf extracts of C. assamensis with different time (A-E) and concentration.

\section{CONCLUSION}

All the conducted experiments in the present study are based on crude extract and are considered to be preliminary in nature. This study suggests that the antioxidant activity of methanol, ethanol and chloroform leaf extracts of $C$. assamensis was found to be significant when compared with the standard and thus the synthetic antioxidants may be replaced 
by the natural antioxidants which don't have serious side effects. So, further scientific studies may be necessary to elucidate detailed mechanism of action and isolate the responsible active principles.

\section{REFERENCES}

1. Varghese, C., Ambrose, C., Veerasamy, R., Hui, P. N. and May, C. S. 2011. Antioxidant activity of hydroalcoholic extract of Labisa pumila Var. alata, an indigenous plant of Malaysia. Int. J. Pharm. Sci. Nanotech. 4, 1418-1422.

2. Khandaker, S., Das, S., Opo, F. A. D. M., Akhter, R. and Shahriar, M. 2016. In vivo pharmacological investigations of the crude extracts of Calamus viminalis (L.). J. Pharmacogn. Phytochem. 5, 263-269.

3. Liu, R. H. 2003. Health benefits of fruit and vegetables are from additive and synergistic combinations of phytochemicals. Am. J. Clin. Nutr. 78, 517S-520S.

4. Devasagayam, T. A., Tilak, J. C., Boloor, K. K., Sane, K. S., Ghaskadbi, S. S. and Lele, R. D. 2004. Free radicals and antioxidants in human health: current status and future prospects. J. Assoc. Physicians India 52, 794- 804.

5. Roussos, P. A. 2011. Phytochemicals and antioxidant capacity of orange (Citrus sinensis (1.) Osbeck cv. Salustiana) juice produced under organic and integrated farming system in Greece. Sci. Hortic. 129, 253-258.

6. Crozier, A. and Ashihara, H. 2006. Plant Secondary Metabolites and the Human Diet. Blackwell Publishing. Oxford. England.

7. Das, A. J., Kumar, R., Athar, M., Rawat, D. S., Kumar, M., Khan, M. A. and Prakash, J. 2013. Ethno medicinal study of threatened plants of Sonitpur district in Assam, North East India. Int. Res. J. Phar. 4, 146-149.

8. Tiwari, P., Kumar, B., Kaur, M., Kaur, G. and Kaur, H. 2011. Phytochemical screening and extraction: a review. Int. Pharm. Sci. 1, 103-104.

9. Laboni, F. R., Mahmud, S., Karim, S., Das, S. and Shahriar, M. 2017. Biological investigations of different leaf extracts of Litsea liyuyingi (Family-Lauraceae). Iosr J. Pharm. and Biol. Sci. 12, 08-17.

10. Shahriar, M., Khair, N. Z., Sheikh, Z., Chowdhury, S. F., Kamruzzaman, M., Bakhtiar, M. S. I., Chisty, S. J. Narjish, S. N., Akhter, R. and Akter, N. 2016. Phytochemical analysis, cytotoxic and in vitro antioxidant activity of Erythrina variegate bark. Eur. J. Med. Plants 11, 1-5.
11. Prieto, P., Pineda, M. and Aguilar, M. 1999. Spectrophotometric quantitation of antioxidant capacity through the formation of a phosphomolybdenum complex: Specific application to the determination of vitamin E. Anal. Biochem. 269, 337-341.

12. Ali, M., Akhter, R., Narjish, S. N., Shahriar, M., and Bhuiyan, M. A. 2105. Studies of preliminary phytochemical screening, membrane stabilizing activity, thrombolytic activity and in-vitro antioxidant activity of leaf extract of $C$. hystrix. Int. J. Pharm. Sci. Res. 6, 2367-2374.

13. Oyaizu, M. 1986. Studies on products of browning reactions: anti-oxidative activities of products of browning reaction prepared from glucosamine. Jpn. J. Nutr. Diet. 44, 307-315.

14. Tania, U. H., Hassan, M. R., Eshita, N. J., Akhter, R. and Shahriar, M. 2016. Evaluation of in vitro antioxidant and in vivo pharmacological activity of leaf extracts of Hoya parasitica (Wall.). J. Appl. Pharm. Sci. 6, 163-170.

15. Yen, G. C. and Chen, H. Y. 1994. Comparison of antimutagenic effect of various tea extracts (green, oolong, pouchong and black tea). J. Food Prot. 57, 54-58.

16. Heim, K. E., Tagliaferro, A. R. and Bobilya, D. J. 2002. Flavonoid antioxidants: Chemistry, metabolism and structure-activity relationships. J. Nutr. Biochem. 13. 572584.

17. Rice-Evans, C., Sampson, J., Bramley, P. M. and Holloway, D. E. 1997. Why do we expect carotenoids to be antioxidants in vivo. Free Radic. Res. 26, 381-398.

18. Oktay, M., Gulcin, I. and Kufrevioglu, O. I. 2003. Determination of in vitro antioxidant activity of fennel (Foeniculum vulgare) seed extracts. LWT - Food Sci. Technol. 36, 263-271.

19. Prasad, M. P. and Rajkumar, R. A. 2014. In vitro antioxidant assay of citrus species using DPPH method. Ind. J. Adv. Plant Res. 1, 1-3.

20. Sudipta, K. M., Swamy, M. K., Balasubramanya, S. and Anuradha, M. 2014. Assessment of genetic fidelity, antioxidant enzyme activity and proline content of micropropagated and field grown plants of Leptadenia reticulata (wight \& arn.)- An endangered medicinal plant. Plant Cell Biotech. Mol. Biol. 15, 127-135.

21. Anonymous. 2003. The wealth of India, First supp series, Vol. VII. New Delhi: Council of Scientific and Industrial Research (CSIR), pp. 273-280. 